REVISTA DE GESTÃO E SECRETARIADO

MANAGEMENT AND ADMINISTRATIVE

PROFESSIONAL REVIEW

ISSN: 2178-9010
Revista GeSec

São Paulo, SP, Brasil

v. 12, n. 2, p. 27-51

maio /ago. 2021

DOI: http://dx.doi.org/10.7769/gesec.v12i2.1209

\title{
A representação das mulheres de carreira no cinema: uma análise sob a
}

\section{ótica das metáforas de desigualdade de gênero}

\section{The portrayal of career women in cinema: an analysis from the perspective of gender inequality metaphors}

\author{
Raimundo Dalmir Luiz de Souza ${ }^{1}$ \\ Rebeca da Rocha Grangeiro ${ }^{2}$ \\ Lucas Emmanuel Nascimento Silva ${ }^{3}$
}

\section{Resumo}

As obras cinematográficas são consideradas eficientes para analisar a sociedade e os ambientes de trabalho, pois refletem a maneira como a sociedade, de modo geral, pensa, age e se comporta sobre determinados assuntos. Diante do papel do cinema de reproduzir e produzir elementos sociais e individuais que envolvem a vida privada e profissional de mulheres que ambicionam ter sucesso nas suas carreiras, o presente artigo possui como objetivo analisar como os filmes retratam os desafios que as mulheres enfrentam para avançar em suas carreiras através das lentes das metáforas da desigualdade de gênero. Os filmes foram acessados por meio do site IMDb (Internet Movie Database), usando os descritores: women, business, career e manager. Considerados filmes produzidos de 1981 a 2019, obtiveram-se 205 peças cinematográficas. Aplicados os critérios de inclusão e exclusão, restaram 39 filmes para análise. Desse modo, a maneira como as mulheres de negócios é representada pelo cinema é discutida por meio das metáforas: Teto de Vidro; Penhasco de Vidro; Fenômeno Abelha Rainha; Parede Materna; Segundo Turno; Labirinto; e Tokenismo. A construção das personagens, segundo as obras visitadas nesse artigo, evidenciou singularidades na abordagem na construção das protagonistas. Todos os filmes analisados nesta pesquisa apresentaram, em alguma cena,

\footnotetext{
${ }^{1}$ Graduando em Administração na Universidade Federal do Cariri (UFCA), Bolsista do Programa de Educação Tutorial de Administração (PETADM).

${ }^{2}$ Doutora em Psicologia, Docente da UFCA.

${ }^{3}$ Mestrando em Administração na Faculdade de Administração, Economia e Contabilidade da Universidade de São Paulo (FEA-USP).
} 
diálogo ou modo como a personagem principal é descrita dentro da narrativa, pelo menos, uma das metáforas abordadas.

Palavras-chave: Desigualdade de Gênero. Análise Fílmica. Metáforas de Gênero. Reprodução de Estereótipos. Liderança.

\begin{abstract}
The cinematographic works are considered efficient to evaluate society and work environments, because they reflect the way society, in general, thinks, acts, and behaves on certain subjects. Faced with the role of cinema in reproducing and producing social and individual elements that involve the private and professional lives of women who aspire to succeed in their careers, this article aims to analyze how films portray the challenges women face in advancing their careers through the lenses of the metaphors of gender inequality. The films were accessed through the $\mathrm{IMDb}$ (Internet Movie Database) site, using the descriptors: women, business, career, and manager. Considering films produced from 1981 to 2019, 205 cinematographic pieces were obtained. Applied the inclusion and exclusion criteria, 39 films were left for analysis. In this way, the way businesswomen are represented by the cinema is discussed through metaphors: Glass Ceiling; Glass Cliff; Queen Bee Phenomenon; Maternal Wall; Second Shift; Labyrinth; and Tokenism. The construction of the characters, according to the works visited in this article, highlighted singularities in the approach to the construction of the protagonists. All the films analyzed in this research presented in some scene, dialogue, or the way the main character is described within the narrative at least one of the metaphors addressed.
\end{abstract}

Keywords: Gender Inequality. Film Analysis. Gender Metaphors. Stereotype Reproduction. Leadership.

\title{
Introdução
}

O cinema se apresenta como instrumento de produção e reprodução de desigualdades de gênero, reforçando estereótipos sexistas, ao retratar a mulher como cuidadora da família e do lar, enquanto o homem é responsável pelo sustento econômico da família (Ezzendeen, 2015). A segunda onda feminista, ocorrida entre as décadas de 60 e 70, apresentou avanços na maneira como as mulheres são representadas na mídia cinematográfica e ampliou a possibilidade de papéis a serem interpretados (Hatton \& Trautner, 2013). Ainda assim, é possível observar baixo 
percentual de mulheres protagonistas se comparado com a presença de homens em papéis principais (Pilcher \& Silverstein, 2015). n, 2015).

Visto que as obras cinematográficas são consideradas eficientes para avaliar a sociedade e os ambientes de trabalho, pois, de modo geral, refletem o modo como se pensa, age e comporta sobre determinados assuntos, servindo de espelho, inclusive, ao representar através das personagens problemas organizacionais reais enfrentados por mulheres em seu cotidiano (Panayiotou, 2010). Além de funcionar como reflexo da sociedade, as mensagens culturais da mídia popular influenciam a percepção dos indivíduos e ensina-os sobre os papéis de gênero (Pennell \& Behm-Morawitz, 2015).

Tais desigualdades impõem desafios para mulheres em contextos de trabalho, que são discutidos na literatura científica por meio de metáforas (Smith et al., 2012). Pesquisadores de diferentes domínios (Psicologia, Ciências Sociais, Ciências Sociais Aplicadas) se utilizam delas para ampliar a compreensão sobre as desigualdades de gênero que as mulheres vivenciam no ambiente de trabalho e, de certo modo, também denunciá-las (Carli \& Eagly, 2016). O emprego das metáforas para explicar as barreiras vivenciadas por mulheres durante sua carreira é fundamental, pois ajuda a direcionar a atenção para problemas importantes (Smith et al., 2012).

A literatura que aborda as dificuldades enfrentadas por mulheres para ascenderem em suas carreiras, através das metáforas, tem destinado maiores esforços na compreensão do fenômeno do Teto de Vidro (cf. Dowling, 2017; Smith et al., 2012), porém outras metáforas também ganharam destaque, a exemplo do Labirinto (cf. Eagly \& Carli, 2007, 2012; Carli \& Eagly, 2016); Penhasco de Vidro (Ryan \& Haslam, 2005, 2007); Fenômeno Abelha Rainha (cf. Derks, Ellemers, Van Laar \& De Groot, 2011; Derks, Van Laar \& Ellemers, 2016). A estrutura generificada das organizações e as barreiras explicitadas por essas metáforas podem moldar a carreira das mulheres e seu status na organização. Os filmes apresentam trajetórias profissionais e comportamentos de mulheres em cargos de liderança, que representam o cotidiano organizacional e por sua vez podem ser explicadas por meio dessas metáforas.

Diante de uma das funções do cinema, no caso a de reproduzir e produzir elementos sociais e individuais que envolvem a vida privada e profissional de mulheres que ambicionam ter sucesso nas suas carreiras, o presente artigo possui como objetivo analisar desafios e barreiras enfrentados por mulheres para avançar em suas carreiras em ambientes corporativos, representados pela indústria cinematográfica, através das lentes das metáforas de desigualdade de gênero.

Esse trabalho se justifica, porque, uma vez que os filmes refletem a sociedade do período em que foram produzidos (Panayiotou, 2010), analisá-los auxilia na compreensão de aspectos 
culturais que envolvem a mulher que atua como gestora; e na identificação dos aspectos que limitam seu desenvolvimento dentro das organizações (Ezzedeen, 2015). O cinema possui uma capacidade reflexiva de retratar as barreiras enfrentadas pelas mulheres, logo, ao evidenciá-las, é possível traçar como tais características são percebidas em determinadas metáforas de desigualdade de gênero (Ezzedeen, 2015). Assim, quando os filmes optam por se concentrar nas lutas das mulheres no ambiente organizacional, o debate através das metáforas, ajuda a entender como barreiras de gênero permeiam as carreiras das mulheres.

É importante analisar o modo como as mulheres são representadas em longas-metragens, pois a percepção midiática da mulher reflete os estereótipos de gênero e os processos históricos de desigualdade vivenciados por elas (Ezzedeen, 2015). Além de pouco representadas como protagonistas das narrativas cinematográficas, na maioria das vezes, os papéis representados por mulheres são criados por homens, logo são a reprodução da visão masculina sobre o comportamento feminino, traduzidas para a grande tela por um grupo de roteiristas e diretores homens (Pilcher \& Silverstein, 2015).

A análise da mulher de negócios no ambiente organizacional através de filmes foi alvo de outros artigos, porém diferente de Dubois (2001), Strachicini (2007) e Spiker (2012), este estudo empreende a análise de um conjunto mais robusto de filmes e não apenas de uma ou duas obras como se observa nos trabalhos das referidas autoras. Também se diferencia da análise realizada por Ezzedeen (2015), pois aplicou critérios diferentes para a seleção dos filmes, o que implicou em uma base de filmes diferente. Outra diferença reside no foco em mulheres em contextos organizacionais e no exame dos filmes a partir de metáforas científicas que explicam a persistência histórica da discriminação de gênero no contexto organizacional.

\section{Referencial Teórico}

Diante da dominação masculina nas organizações, observa-se desigualdade de gênero que impõe barreiras para o desenvolvimento profissional feminino. A fim de ampliar a compreensão de barreiras vivenciadas por mulheres em contextos organizacionais e proporcionar reflexão sobre as adversidades impostas à ascensão feminina, pesquisadores(as) de áreas como psicologia, ciências sociais e administração criaram metáforas. Elas são consideradas ferramentas úteis na explicação de fenômenos sociais, pois auxiliam na estruturação de conhecimentos básicos sobre o mundo, fornecendo novos insights, uma vez que concentram a atenção sobre questões sociais relevantes (Smith et al., 2012). As principais 
metáforas encontradas nos filmes analisados foram: teto de vidro, penhasco de vidro, abelha rainha, labirinto, parede materna, segundo turno e tokenismo.

O Teto de Vidro (Glass Ceiling) se refere às barreiras invisíveis que as mulheres enfrentam no local de trabalho que as mantêm nos níveis mais baixos da estrutura organizacional (Dowling, 2017). Esses obstáculos estão presentes diariamente e são responsáveis pela falta de mulheres em posições de liderança (Powell, 2012). A maioria das explicações para a existência do Teto de Vidro destaca estereótipos e discriminação contra elas (Smith et al., 2012).

Ainda que algumas mulheres tenham obtido êxito em quebrar o teto de vidro, Ryan e Haslam $(2005,2007)$ descobriram que as mulheres são frequentemente contratadas para posições de liderança precárias, para as quais, algumas vezes, homens já teriam recusado o convite para ocupar o referido posto. A partir da observação empírica da contratação de mulheres para postos de responsabilidade quando a situação econômica da empresa é desfavorável, Ryan e Haslam $(2005,2007)$ introduziram a metáfora do Penhasco de Vidro (Glass Cliff). Os autores explicam que, apesar do progresso significativo em níveis educacionais e no mercado de trabalho, as mulheres ainda são vistas como impróprias para os papéis de liderança. As empresas já estão em crise no momento da contratação da gestora, porém se cria a imagem de que a falência da organização é resultado do mau gerenciamento por parte das mulheres (Ryan \& Haslam, 2005, 2007).

Por não concordarem que o Teto de Vidro representasse da maneira mais adequada as barreiras organizacionais impostas pela desigualdade de gênero, Eagly e Carli (2007) propuseram uma metáfora denominada Labirinto (Labyrinth), buscando ilustrar os obstáculos no caminho das mulheres para os papéis de liderança. Fazendo uma comparação com a figura de um labirinto, as autoras discutem como, em quais mudanças no local de trabalho, a metáfora do Teto de Vidro pode não ser muito precisa para entender os obstáculos atuais que as mulheres enfrentam. Além disso, o Labirinto é o caminho cheio de obstáculos que as mulheres enfrentam e, portanto, pode ser diferente para cada mulher, com percursos e barreiras variadas (Eagly \& Carli, 2007, 2012).

O Fenômeno Abelha Rainha (Queen Bee Phenomenon) consiste em um reflexo sintomático da segregação de gênero dentro das organizações (Derks et al., 2016). Para obter êxito profissional, a mulher busca assemelhar sua postura ao estereótipo masculino, adquirindo traços agency (comportamentos comumente associados à figura masculina, a exemplo de ambição, agressividade e competitividade). Outra característica da líder abelha rainha diz respeito a elas se oporem à ascensão de mulheres subordinadas ou em início da carreira, pois 
as consideram como menos comprometidas com suas carreiras e menos dispostas a fazerem escolhas em favor de seus desenvolvimentos profissionais, quando comparadas a seus pares homens (Derks et al., 2016).

À medida que as mulheres alcançam posições dominadas por homens, às vezes são vistas como símbolos, tendo menos status na organização e menos oportunidades de alcançar a igualdade (Zimmer, 1998). A metáfora do Tokenismo (Tokenism) surgiu na tentativa de buscar explicar os porquês dessa liderança feminina ter apenas um valor simbólico e, por isso, não representar necessariamente um avanço rumo à igualdade de gênero organizacional (Zimmer, 1998).

Para O’Neil, Hopkins e Bilimoria (2008), a carreira das mulheres é significativamente mais complexa que a dos homens, pois família e trabalho são duas dimensões interconectadas para elas. Nesta perspectiva, iniciou-se uma discussão em torno desse Segundo Turno (Second Shift) feminino, que posteriormente passou a ser debatido como uma alegoria para explicar essa dupla jornada (Hochschild \& Machung, 1989). A metáfora do Segundo Turno discute como as mulheres têm um turno remunerado na organização e um segundo turno não remunerado no domicílio (Brailey \& Slatton, 2019). Isso resulta em um equilíbrio mais difícil de alcançar, pois as mulheres têm responsabilidades significativas em ambos.

Ademais, focando nas mães que trabalham, Williams (2004) desenvolveu a metáfora da Parede Materna (Maternal Wall) e discutiu o fenômeno em que há discriminação contra essas mulheres, porque elas são vistas como mais emocionais e menos competentes, e os empregadores não querem separá-las dos filhos, sendo-lhes negadas oportunidades crescentes na empresa. A Figura 1 resume as metáforas apresentadas nesta seção.

\begin{tabular}{c|c|c}
\hline Metáfora & Conceito & Autores \\
\hline Teto de Vidro & $\begin{array}{c}\text { Descreve os obstáculos invisíveis que as mulheres enfrentam e que } \\
\text { limitam seu avanço às principais posições de liderança. }\end{array}$ & $\begin{array}{c}\text { Dowling } \\
(2017)\end{array}$ \\
\hline $\begin{array}{c}\text { Penhasco de } \\
\text { Vidro }\end{array}$ & $\begin{array}{c}\text { Refere-se à nomeação de mulheres para cargos de liderança } \\
\text { precários, criando a percepção de que as mulheres são } \\
\text { subqualificadas para serem líderes. }\end{array}$ & $\begin{array}{c}\text { Ryan e Haslam } \\
(2005,2007)\end{array}$ \\
\hline Labirinto & $\begin{array}{c}\text { Diz respeito aos inúmeros desafios que as mulheres enfrentam em } \\
\text { suas trajetórias de carreira em todos os níveis hierárquicos pelos } \\
\text { quais elas passam A metáfora também busca representar os diferentes } \\
\text { caminhos que as mulheres podem percorrer. }\end{array}$ & $\begin{array}{c}\text { Eagly e Carli } \\
(2007,2012)\end{array}$ \\
\hline
\end{tabular}




\begin{tabular}{c|c|c}
\hline Abelha Rainha & $\begin{array}{c}\text { Caracteriza-se pela abordagem das mulheres à imagem masculina } \\
\text { em busca de ascensão organizacional, distância física e psicológica } \\
\text { feminina e endosso do modelo patriarcal. }\end{array}$ & $\begin{array}{c}\text { Derks et al., } \\
(2016)\end{array}$ \\
\hline Tokenismo & $\begin{array}{c}\text { As mulheres em posições altamente ocupadas pelos homens estão em } \\
\text { uma posição de "símbolo", tendo influências negativas e } \\
\text { incapacidade de alcançar a igualdade. }\end{array}$ & Zimmer (1998) \\
\hline Segundo Turno & $\begin{array}{c}\text { As mulheres trabalham em dois turnos. O primeiro é pago na } \\
\text { organização e o segundo não é remunerado no domicílio. }\end{array}$ & $\begin{array}{c}\text { Brailey e } \\
\text { Slatton (2019) }\end{array}$ \\
\hline Parede Materna & $\begin{array}{c}\text { Refere-se à discriminação que as mães que trabalham enfrentam no } \\
\text { local de trabalho, pois são vistas como mais emocionais, menos } \\
\text { competentes e, portanto, não têm a oportunidade de crescer porque os } \\
\text { empregadores não querem separar a mãe das crianças. }\end{array}$ & $\begin{array}{c}\text { Williams } \\
(2004)\end{array}$ \\
\hline
\end{tabular}

Figura 1. Metáforas

Fonte: Autores da pesquisa.

\section{Método}

Para selecionar os filmes analisados na pesquisa, os autores recorreram ao banco de dados cinematográficos disponibilizado no site IMDb (Internet Movie Database). Posteriormente foram selecionados filmes usando, para a busca, os seguintes descritores: women (mulheres), business (negócios), career (carreira) e manager (gerente, administradora). Apenas foram considerados filmes produzidos de 1981 a 2019, pois correspondem a um panorama pós segunda onda feminista. No período delimitado, observa-se ampliação da possibilidade de papéis interpretados por mulheres (Hatton \& Trautner, 2013), que antes se circunscreviam à vida privada (dona-de-casa, esposa e mãe). Utilizando essas palavras-chave, foram selecionadas 205 peças cinematográficas.

Após a seleção inicial, foram utilizados os seguintes itens para eleger apenas longasmetragens que atenderam ao objetivo deste artigo: i) todos os filmes apresentaram pelo menos uma protagonista; ii) os filmes tinham como pano de fundo o ambiente organizacional; iii) o foco narrativo da personagem feminina principal era sua carreira, e não ter ou ser apenas interesse romântico; e iv) a peça cinematográfica passou pelo Teste de Bechdel, como um método de provar que a história da personagem principal não envolve apenas uma figura masculina.

O Teste de Bechdel, criado em 1985 pela cartunista norte-americana Alison Bechdel, que expressou essa ideia dentro da série de quadrinhos Dykes to Watch Out For (Lésbicas para 
se Observar ou Observações Lésbicas), também é conhecido como Teste de Bechdel/Wallace, Regra de Bechdel, Lei de Bechdel ou Medida de Filme Mo (Mo Movie Measure). Ele consiste em três critérios a partir dos quais qualquer filme ou outra mídia podem ser avaliados (Agarwal et al., 2015). São eles: a presença de pelo menos duas personagens femininas, a existência de um diálogo entre elas e, principalmente, que a conversa não esteja relacionada, direta ou indiretamente, a homens. O teste foi desenvolvido para avaliar a presença das mulheres nos filmes. Alguns pesquisadores o utilizaram com o objetivo de mostrar se as personagens femininas possuem um enredo para além de circundar a narrativa de um personagem masculino, permitindo a exposição da desigualdade de gênero em filmes (Agarwal et al., 2015).

Foram excluídos filmes pertencentes aos seguintes gêneros: ficção científica, fantasia, horror, musical e animações, com o intuito de manter as peças ficcionais mais próximas das das situações vivenciadas por mulheres em contexto cotidiano. Porém, como o objetivo desta pesquisa é traçar um paralelo entre o retrato ficcional feminino em filmes e a realidade, foram excluídos os documentários. As obras cinematográficas baseadas em fatos reais e as adaptações literárias foram incluídas na análise, no entanto, apenas a narrativa audiovisual presente no filme foi considerada na pesquisa. Aplicados os critérios de exclusão, restaram 39 filmes para análise, que se encontram na Tabela 1.

Tabela 1:

Lista dos Filmes Analisados

\begin{tabular}{lcc}
\hline Ano & Título original & Título brasileiro \\
\hline 1981 & Absence of Malice & Ausência de Malícia \\
1985 & Jagged Edge & O Fio da Suspeita \\
1987 & Baby Boom & Presente de Grego \\
1987 & Broadcast News & Nos Bastidores da Notícia \\
1991 & The Silence of the Lambs & O Silêncio dos Inocentes \\
1995 & Copycat & Copycat - A Vida Imita a Morte \\
1996 & Up Close \& Personal & Íntimo e Pessoal \\
1997 & Picture Perfect & Paixão de Ocasião \\
2000 & Miss Congeniality & Miss Simpatia \\
2000 & The Contender & A Conspiração \\
2000 & Erin Brockovich & Erin Brockovich - Uma Mulher de Talento \\
2002 & Murder By Numbers & Cálculo Mortal \\
2003 & Legally Blonde 2 & Legalmente Loira 2 \\
2005 & Miss Congeniality 2 & Miss Simpatia 2
\end{tabular}


2006

2007

2008

2008

2009

2010

2010

2010

2011

2011

2012

2012

2013

2015

2015

2016

2016

2016

2017

2017

2017

2017

2018

2019

2019
The Devil Wears Prada

Blonde Ambition

Nothing But the Truth

Untraceable

New in Town

Fair Game

Morning Glory

Unthinkable

I Don't Know How She Does It

The Iron Lady

Zero Dark Thirty

Passion

The Heat

The Intern

Truth

Equity

Toni Erdmann

Hidden Figures

Miss Sloane

Molly's Game

Numéro Une

The Post

Saint Judy

Little

Bombshell
O Diabo Veste Prada

Ninguém Segura Essa Garota

Faces da Verdade

Sem Vestígios

Recém Chegada

Jogo de Poder

Uma Manhã Gloriosa

Ameaça Terrorista

Não Sei Como Ela Consegue

A Dama de Ferro

A Hora Mais Escura

Paixão

As Bem Armadas

Um Senhor Estagiário

Conspiração e Poder

Mercado de Capitais

As Faces deToni Erdmann

Estrelas Além do Tempo

Armas na Mesa

A Grande Jogada

A Número Um

The Post - A Guerra Secreta

Justiça Sem Fronteiras

A Chefinha

O Escândalo

Fonte: Autores da pesquisa.

Para realizar a análise, os autores assistiram a todos os filmes, mais de uma vez, conforme sugerido por Vanoye e Goliot-Lété (1994) para realização de análise de filmes. Foram examinados os embargos enfrentados durante o desenvolvimento do protagonista, traçando assim um paralelo com os problemas reais que as mulheres enfrentam em suas carreiras e correlacionando-os pela metodologia subsequente.

Primeiro, foram observadas as roupas, a maquiagem, os sapatos, tudo o que compõe a aparência do personagem, bem como os cenários, o ambiente de trabalho e a composição das pessoas nele, homens e mulheres. As imagens de filmes fornecem dados relevantes para 
compreensão de fenômenos sociais e portanto são passíveis de análise qualitativa (Loizos, 2002). Assim, observou-se a maneira como a mulher é descrita sob essa perspectiva durante a narrativa, em todas as heroínas, em diferentes graus de poder dentro da organização.

Segundo, foi analisada a interação entre as protagonistas femininas e os homens que as cercam nos filmes, podendo estar em um contexto organizacional ou de vida pessoal (maridos, pais e namorados). Da mesma forma, foi levado em consideração como elas se comportam em relação a outra personagem feminina a fim de entender a conexão entre gênero e poder, ou seja, se há alguma diferença na relação mulher/homem e mulher/ mulher. Finalmente, foram analisados os diálogos em torno da personagem feminina, a fim de capturar as barreiras mais recorrentes, o modo como elas são abordadas pela narrativa do filme e nos diálogos do protagonista com homens e com outras mulheres.

\title{
Resultados e Discussão
}

\subsection{A representação das mulheres}

O filme Baby Boom (Presente de Grego, 1987) começa com o seguinte monólogo narrado sobre a evolução da mulher na sociedade e sua ascensão à ambientes organizacionais, em voice-over (locução de fundo), para apresentar a personagem J. C. Wiatt (Diane Keaton):

\begin{abstract}
$53 \%$ dos trabalhadores americanos são mulheres, três gerações de mulheres que mudaram mil anos de tradição, desde pequenas lhes diziam que se casem com médicos e advogados, mas foram elas que se tornaram médicas e advogadas. Saíram da cozinha e entraram nas salas dos executivos. Os sociólogos afirmam que a nova mulher trabalhadora é um fenômeno natural. Veja J. C. Wiatt, por exemplo, formada primeira da sua turma em Yale, possui um MBA em Harvard, com um escritório na esquina da avenida $58^{\circ} \mathrm{com}$ a Park. Ela trabalha de 5 às 9 , faz seis dígitos por ano e eles a chamam de "tigresa".
\end{abstract}

Entretanto, o primeiro diálogo entre a personagem J. C. Wiatt (Diane Keaton) e seu chefe, Fritz Curtis (Sam Wanamaker), expõe que, apesar da sua competência profissional, como mulher existem certas concessões às quais ela deve se submeter para se tornar bem sucedida em um ambiente empresarial. "Um homem pode ter sucesso e ter uma vida pessoal [...] eu posso ter tudo", fundamenta ele. Tal argumento é exemplo de uma barreira de gênero que mulheres enfrentam no ambiente corporativo. As barreiras estão presentes, principalmente, em ambientes predominantemente masculinizados tendo como base a disparidade do poder exercido (Derks et al., 2011). 
Por exemplo, em The Silence of the Lambs (O Silêncio dos Inocentes, 1991), o vínculo entre Clarice Starling (Jodie Foster) e Hannibal Lecter (Anthony Hopkins) expressa como apesar de a agente do FBI ser a responsável por interrogá-lo, a construção da história estabelece Lecter como superior intelectualmente à personagem de Foster, não obstante o papel de autoridade pertença a ela. A autoridade de Hannibal é evidenciada toda vez que o filme enquadra os dois personagens em uma cena de diálogo. Clarice é mostrada sob um plano inferior e sempre é estimulada pelos conselhos dele (Figura 2). Contudo, a relação StarlingLecter é considerada construtiva para o desenvolvimento da protagonista, pois o personagem de Hopkins é o único que a encoraja e não julga sua ambição profissional (Dubois, 2001).

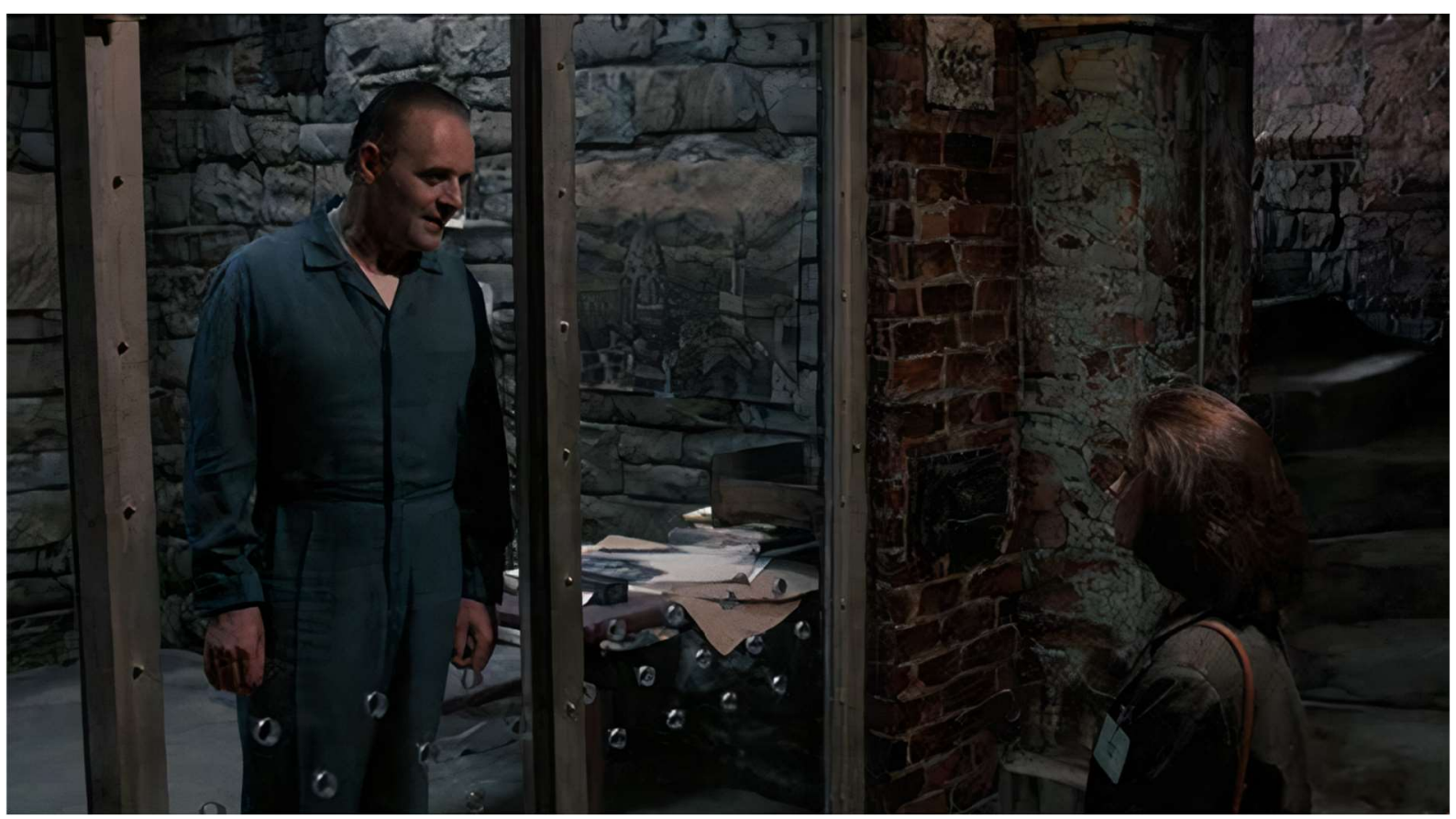

Figura 2. Primeiro encontro de Clarice e Hannibal

Fonte: O Silêncio dos Inocentes, 1991. Captura de tela realizada pelos autores.

Nas obras analisadas, ideais masculino e feminino são manipuláveis, contrapostos, determinando a sua relação, e colaborando na influência dominante do homem e submissa de mulher como algo natural (Schippers, 2007). Por sua vez, a feminilidade aparece não pela roupa, e sim, nos sapatos, especificamente, os saltos, usados por todas as personagens como concessão, ou mesmo imposição feita pelos personagens homens, a fim de manipular o ideal feminino. Por exemplo, em Miss Simpatia (2000) e em O Diabo Veste Prada (2006), as duas protagonistas são forçadas a usar saltos altos para se adequarem ao ambiente de trabalho (Figura 3). Neste, os saltos são oferecidos à Andy (Anne Hathaway) no primeiro dia de trabalho por Nigel (Stanley Tucci), mas ela os recusa a princípio, e se refere às mulheres que trabalham na revista como "Clarks", devido ao barulho produzido pelos saltos. Segundo Spiker (2012) a 
personagem de Hathaway representa a visão patriarcal da sociedade, e assim, refletindo comportamentos machistas no começo do longa, sendo sua principal transformação na trama, entender a sua carreira como prioridade.

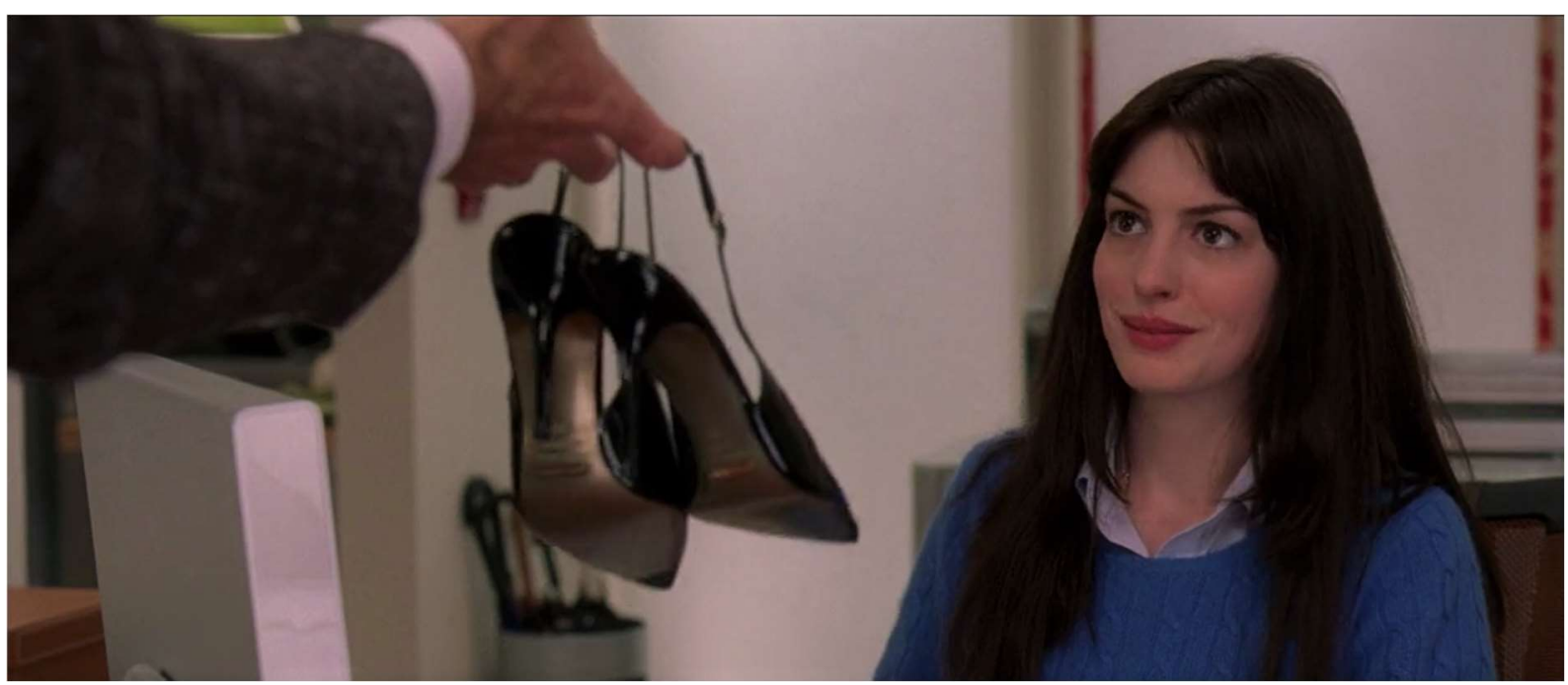

Figura 3. Andy recebe um par de saltos em seu primeiro dia de trabalho

Fonte: O Diabo Veste Prada, 2006. Captura de tela realizada pelos autores.

É usual dentro das ficções observadas a necessidade de uma validação masculina sobre a fala de uma mulher, mesmo que a mesma esteja ocupando um cargo de liderança. Por exemplo, no filme New in Town (Recém Chegada, 2009), a autoridade e a liderança da personagem feminina apresentada por Lucy Hill (Renée Zellweger) é ridicularizada durante a narrativa. No início, quando ela chega à cidade para assumir o cargo de chefia na fábrica, tanto Ted Mitchell (Harry Connick Jr.), representante local do sindicato dos trabalhadores e, principalmente, Stu Kopenhafer (J.K. Simmons), encarregado pela linha de produção, são colocados como antagonistas à liderança da protagonista, inclusive por ela ser mulher. Posto isso, é a personagem principal feminina que tem de buscar a ajuda dos personagens homens para conseguir evitar a falência da fábrica.

Caso análogo ocorreu em Erin Brockovich (2000). Mesmo sendo ela quem descobre a irregularidade na companhia de água, é através de seu patrão, Ed Marsty (Albert Finney), e depois Kurt Potter (Peter Coyote), ambos personagens masculinos, que seu trabalho é reconhecido. Uma vez que esses filmes retratam personagens femininas em diferentes graus organizacionais, mesmo quando ocupado um cargo de liderança, com a personagem de Zellweger, os homens que as rodeiam dentro do ambiente de trabalho exercem uma liderança sobre elas. A autoridade masculina é definida pela disposição e nivelação das funções, atividades, ocupações, apoiando-se na dialética estruturada dos gêneros, expondo diferentes arcabouços de validação sexual entre homens e mulheres (Laufer, 2005). 
Observou-se na análise dos filmes que compõem a base desse artigo que, quando se tem uma heroína como centro da narrativa, existem barreiras e peculiaridades únicas que não foram observadas em filmes protagonizados por homens. No ambiente organizacional, a imagem da mulher foi fixada de um ponto de subordinação ou desqualificação de sua competência profissional baseado no fator sexual. Isso decorre como consequência do modelo patriarcal no qual a sociedade foi construída, cuja cultura do binarismo (homem/mulher) posiciona os gêneros de modo antagônico, favorecendo os homens com status superior, o que há muito é relegado às mulheres (Carvalho, 2016).

\subsection{Metáforas de gênero}

No aspecto cinematográfico analisado, a quebra do Teto de Vidro tornou-se cada vez mais comum ao longo das décadas observadas. Nos anos 80, apenas em Baby Boom (1987) a heroína está tentando romper essa barreira, mas sem sucesso; igualmente, nos anos 90, apenas um filme traz essa metáfora em perspectiva, The Contender (A Conspiração, 2000), ao narrar a indicação de uma mulher para concorrer à vice-presidência dos Estados Unidos. Na primeira década do século XXI, The Devil Wears Prada (O Diabo Veste Prada, 2006) mostrou Miranda Priestly (Meryl Streep) como CEO e editora-chefe de moda revista; New in Town (Recém Chegada, 2009), apresentou Lucy Hill (Renée Zellweger) responsável por uma subsidiária de uma empresa de alimentos; e em Unthinkable (Ameaça Terrorista, 2010), Helen Brody (CarrieAnne Moss) é responsável por liderar uma investigação antiterrorista. Na década de 2010, identificou-se a ampliação da quantidade de filmes, que equivale ao somatório de todas as outras décadas. A ruptura do teto de vidro está presente em I Don't Know How She Does It (Não Sei Como Ela Consegue, 2011), The Iron Lady (A Dama de Ferro, 2011), Passion (Paixão, 2012), The Intern (Um Senhor Estagiário, 2015), Equity (Mercado de Capitais, 2016), Hidden Figures (Estrelas Além do Tempo, 2016), Toni Erdmann (As Faces de Toni Erdmann, 2016), Molly's Game (A Grande Jogada, 2017), Numéro Une (A Número Um, 2017), The Post (The Post - A Guerra Secreta, 2017), Saint Judy (Justiça Sem Fronteiras, 2018) e Little (A Chefinha, 2019).

A mulher ser retratada no cinema como uma profissional de sucesso, de forma não estereotipada, é um passo adiante para amenizar ou até mesmo desconstruir a imagem negativa relacionada a mulheres de negócios (Ezzedeen, 2015). Há uma evolução progressiva na igualdade profissional entre homens e mulheres, com sinais crescentes de participação feminina nas organizações, mas ainda existe uma discrepância evidente (Laufer, 2005). Posto isso, é 
possível notar uma evolução na representação de mulheres em cargos de liderança através dos filmes analisados, quando se compara as obras produzidas a partir dos anos 2000 , com as décadas de 1980 e 1990. Nas primeiras duas décadas analisadas, as personagens são hostilizadas tanto por homens quanto por outras mulheres por trabalharem constantemente e são consideradas menos mulheres por optar por ter um emprego. Ao contrário, os filmes da década de 2000 apresentam narrativas com mulheres ascendendo em suas carreiras, sem medo de serem taxadas como ambiciosas, de modo negativo, e com menor obrigação de ter marido e filhos.

No entanto, nem sempre que uma mulher consegue quebrar o Teto de Vidro as circunstâncias sob as quais essa ascensão acontece podem ser consideradas positivas. É muito comum a promoção ocorrer em uma situação de desvantagem para a mulher, metáfora denominada Penhasco de Vidro (Ryan \& Haslam, 2005). Dentro da cinematografia analisada foi percebida a presença dessa metáfora em cinco filmes, sendo eles, The Contender (A Conspiração, 2000), New in Town (Recém Chegada, 2009), Morning Glory (Uma Manhã Gloriosa, 2010), The Iron Lady (A Dama de Ferro, 2011) e The Post (The Post - A Guerra Secreta, 2017).

Apesar da oportunidade de ascensão surgir em condição desfavorável, às mulheres tendem a aceitá-la, enxergando-a como único meio de mostrar sua competência profissional (Ryan \& Haslam, 2005). The Contender (A Conspiração, 2000) relacionou-se a essa metáfora em razão de a protagonista, Laine Hanson (Joan Allen), receber o convite para se candidatar a vice-presidente logo após um escândalo envolvendo o nome do Governador Jack Hathaway (William Petersen), favorito ao cargo. Em New in Town (Recém Chegada, 2009), Lucy Hill (Renée Zellweger) voluntariou-se a gerenciar uma divisão à beira da falência, depois da recusa de todos os seus colegas homens. Becky Fuller (Rachel McAdams), em Morning Glory (Uma Manhã Gloriosa, 2010), foi aceita como produtora executiva de um programa de notícias matutino devido ao baixo desempenho de audiência que ele vinha apresentando. Em The Iron Lady (A Dama de Ferro, 2011), Margaret Thatcher (Meryl Streep) ascendeu ao cargo de primeira-ministra britânica em meio a uma crise econômica do país. Por último, em The Post (The Post - A Guerra Secreta, 2017), o falecimento do editor-chefe e proprietário de um jornal gera instabilidade no ambiente corporativo. Nesse contexto, Kay Graham (Meryl Streep) assume o cargo de editora-chefe, tornando-se a primeira mulher a ocupar tal posto nesse jornal.

Em 35 dos 39 longas-metragens analisados, mulheres que almejam desenvolvimento profissional dentro das organizações optam por se relacionar com líderes homens. Esse fato presente nos filmes já foi identificado na literatura sobre gênero e trabalho, onde se destaca que exercer o papel de líder é melhor percebido quando relacionado a uma figura masculina, tanto 
na visão de homens quanto na visão de mulheres (Laufer, 2005). Nesse sentido, a Síndrome de Abelha Rainha surgiu como metáfora para explicar as razões pelas quais as mulheres se afastam do estereótipo de gênero feminino no lócus organizacional em busca de ascender a cargos mais altos (Derks et al., 2011).

Foi possível observar a Síndrome de Abelha Rainha ocorrendo nos seguintes filmes do presente artigo: Up Close \& Personal (Íntimo e Pessoal, 1996), Legally Blond 2 (Legalmente Loira 2, 2003), The Devil Wears Prada (O Diabo Veste Prada, 2006), Blonde Ambition (Ninguém Segura Essa Garota, 2007), Passion (Paixão, 2012), Equity (Mercado de Capitais, 2016), Little (A Chefinha, 2019) e Bombshell (O Escândalo, 2019).

Em Legally Blond 2 (Legalmente Loira 2, 2003), as características de Abelha Rainha podem ser observadas na personagem Victoria Rudd (Sally Field), manifestando-se quando ela tenta impedir que o projeto de lei proposto por Elle Woods (Reese Witherspoon) seja aprovado no congresso, a fim de não prejudicar sua carreira e usando a situação com o objetivo de autopromoção. Ao ser questionada por Elle sobre o motivo de estar fazendo lobby contra ela, Rudd declara: "sobrevivência", e complementa, "você não tem ideia do que é preciso para chegar aqui e ficar aqui".

A personagem Christine (Rachel McAdams) de Passion (Paixão, 2012), evidencia a metáfora quando usurpa uma ideia de sua assistente, Isabelle (Noomi Rapace), com o objetivo de conseguir uma promoção na empresa, "você está chocada porque eu roubei o crédito da sua ideia, mas acho que teria feito o mesmo no meu lugar. [...] Isso não é traição, isso são negócios, Isabelle, estamos no mesmo time, você tem talento e eu o usei da melhor maneira". Ao optar por um modelo feminino que acolhe abertamente essa estrutura sexista, refutando a existência de tal diferenciação a outra mulher, perpetua-se a condição patriarcal da divisão de poder (Derks et al., 2016).

Outro exemplo de um comportamento de abelha rainha é da personagem Miranda Priestly (Meryl Streep), The Devil Wears Prada (O Diabo Veste Prada, 2006). Ao ter seu posto de editora-chefe da revista de moda Runway ameaçado por Jacqueline Follet (Stephanie Szostak), Miranda impede-a, oferecendo-lhe outro cargo. "A verdade é, não há ninguém capaz de fazer o que eu faço", argumenta a personagem. A conjuntura do ambiente empresarial, especialmente, a intimidação feminina sobre as pretensões profissionais opostas às delas, desencadeia na exteriorização de preconceito de gênero: mulheres sentem-se ameaçadas pela ascensão de outras mulheres (Derks et al., 2011).

Ataques pessoais existentes nos filmes podem ser considerados como uma barreira organizacional à mulher, sendo legítimo associá-los à metáfora do Labirinto abordada por Carli 
e Eagly (2016), como um tipo de obstáculo enfrentado por mulheres em seus empregos que também pode ser percebido na ótica cinematográfica, ocorrendo de maneiras diferentes. $\mathrm{O}$ assédio, moral e sexual, foi repetidamente percebido nas obras como o principal desafio organizacional enfrentado pelas protagonistas à ascensão profissional.

O assédio moral apresentou-se tanto nas relações homem-mulher quanto mulhermulher. Assediar moralmente uma pessoa ocorre quando há coação deliberada de alguém a situações envergonhantes e constrangedoras, sob uma relação hierárquica de poder (O'LearyKelly \& Bowes-Sperry, 2001). Tal prática foi identificada em Passion (Paixão, 2012) quando Christine (Rachel McAdams) humilha Isabelle (Noomi Rapace) durante uma confraternização da empresa. Em The Devil Wears Prada (O Diabo Veste Prada, 2006), Miranda (Meryl Streep) ameaça demitir Andy (Anne Hathaway) caso ela não consiga o manuscrito inédito de Harry Potter. Em Little (A Chefinha, 2019), Jordan Sanders (Regina Hall) destrata todos os seus funcionários, ofendendo-os com apelidos.

Já assediar sexualmente, percebido apenas na relação homem-mulher, consiste em investidas de cunho sexual não recíprocas, podendo ser verbal ou físicas (O’Leary-Kelly \& Bowes-Sperry, 2001). O assédio sexual foi identificado em The Silence of the Lambs (O Silêncio dos Inocentes, 1991), Clarice Starling (Jodie Foster) escuta diversos "elogios" de cunho sexual durante uma conversa profissional e recebe um convite para sair, repetidamente, apesar de sua recusa. Em Morning Glory (Uma Manhã Gloriosa, 2010), Paul McVee (Ty Burrell) pergunta a Becky Fuller (Rachel McAdams), qual o número ela calça e depois se oferece para tirar fotos de seus pés.

Bombshell (O Escândalo, 2019) traz seu enredo envolto nas denúncias de assédio sexual contra o CEO da Fox News, Roger Ailes (John Lithgow), iniciadas por Gretchen Carlson (Nicole Kidman). O filme aborda como o poder e a influência desse homem coagiu mulheres a se calarem durante tanto tempo, estruturado no medo de terem suas carreiras prejudicadas e ficarem marcadas como hostis, demonstrado durante um diálogo com Megyn Kelly (Charlize Theron) que, ao recusar uma investida, é questionada sobre quando seu contrato vence, como forma de intimidação. Ao assediar Kayla Pospisil (Margot Robbie) ele usa a desculpa da televisão ser uma mídia visual. Quando Gretchen Carlson (Nicole Kidman) aparece sem maquiagem no ar, em seu programa de TV, Roger diz que "ninguém quer assistir uma mulher de meia-idade suando por causa de sua menopausa", e logo após ela é demitida.

Não obstante, observou-se o Argumentum ad hominem (argumento contra a pessoa), uma falácia de argumentação muito usual dentro da retórica. Esse comportamento é caracterizado por palavras ou expressões, geralmente de baixo calão, que visam atacar a pessoa 
no âmbito pessoal. Ele foi observado nos filmes analisados como outra manifestação da metáfora do Labirinto. Como exemplo, referir-se à primeira ministra Margaret Thatcher (Meryl Streep) como "dama de ferro", a Elle Woods (Reese Witherspoon) como "barbie do capitólio", a Miranda Priestly (Meryl Streep) por "mulher-dragão" ou "rainha de gelo", acusar Megyn Kelly (Charlize Theron) de menstruar de raiva, ou mesmo, usar de palavras de baixo calão, como "porcas gordas", "cadelas", "fétidas" e "animais nojentos", com intuito de ofender a mulher por causa do seu gênero.

A imagem dos homens de carreira de sucesso nas organizações estabelecida nos filmes não questiona a ausência de obrigações domésticas e familiares dos personagens masculinos (Panayiotou, 2010). Por outro lado, não há muito tempo, a única função que uma mulher poderia exercer era a materna. Embora se observe mudança na ocupação de espaços organizacionais, a maternidade segue como uma obrigação principalmente das mulheres (Canabarro \& Salvagni, 2015). Nessa perspectiva, a metáfora da Parede Materna foi observada nos filmes estudados como uma barreira à ascensão profissional feminina. As consequências dessa alegoria desenvolvida por Hochschild e Machung (1989) permanecem quase que inalteradas desde a década de 80 .

A dicotomia entre a dupla jornada feminina: ter uma carreira bem sucedida e a maternidade, foram abordadas como tema central nestes dois filmes: Baby Boom (Presente de Grego, 1987), da década de 1980, e I Don't Know How She Does It (Não Sei Como Ela Consegue, 2011), da década de 2010. Porém, enquanto no longa de 1987 a personagem de Diane Keaton se vê obrigada a abandonar sua carreira para cuidar da filha, no de 2011, Kate (Sarah Jessica Parker) tenta ao máximo conciliar ambas jornadas. Um dos principais efeitos colaterais dessa síndrome é a impossibilidade das mulheres romperem o Teto de Vidro (Williams, 2004). Apesar de o Teto de Vidro ter sido quebrado na trama de The Intern (Um Senhor Estagiário, 2016), Jules Ostin (Anne Hathaway), se vê pressionada pelo marido a contratar um $C E O$ com o intuito de gerenciar seu e-commerce, e assim, abdicar de seu cargo de liderança, recuando o avanço profissional que havia conquistado para dedicar mais tempo a sua família.

A Parede Materna é colocada como um empecilho à mulher dentro das organizações e pode ser evidenciada nas falas: "Um homem diz que vai sair do escritório e cuidar do seu filho, todos acham que é o exemplo paterno a ser seguido. A mulher diz que precisa sair para cuidar do filho doente, acham-na desorganizada, irresponsável e alguém que não tem comprometimento suficiente", diz Allison (Christina Hendricks), melhor amiga da personagem de Sarah Jessica Parker, em I Don't Know How She Does It (Não Sei Como Ela Consegue, 
2011). Em The Contender (A Conspiração, 2000), Laine Hanson (Joan Allen) é questionada por Shelly Runyon (Gary Oldman) sobre o seu comprometimento profissional, "se engravidasse novamente, voltaria a gozar de licença maternidade?", Hanson contra argumenta, “não acredito que mulheres devam ser penalizadas por terem filhos". O julgamento das capacidades de gênero, dentro do locus organizacional, exalta certas características quando apresentadas por homens enquanto as rechaça quando apresentadas por mulheres (Laufer, 2005).

Além da Parede Materna, foi percebida a presença de outra metáfora complementar, o Segundo Turno, ou seja, a responsabilidade pelos afazeres domésticos e cuidado com os filhos como um acréscimo à jornada de trabalho (Brailey \& Slatton, 2019). Se antes não lhes era concedido acesso às posições dentro das empresas (Canabarro \& Salvagni, 2015), desde a década de 70, mesmo com as mudanças no perfil organizacional da mulher, ser mãe e esposa ainda é uma função acrescida e intrínseca às mulheres. Essa dinâmica esteve presente nas narrativas apontadas para Parede Materna e também em Jagged Edge (O Fio da Suspeita, 1985), Erin Brockovich (2000), Nothing But the Truth (Faces da Verdade, 2008), Untraceable (Sem Vestígios, 2008), The Iron Lady (A Dama de Ferro, 2011), Truth (Conspiração e Poder, 2015), Hidden Figures (Estrelas Além do Tempo, 2016), Numéro Une (A Número Um, 2017), Saint Judy (Justiça Sem Fronteiras, 2018).

Por outro lado, também foi percebido que a ausência do elemento família também é passível de críticas à mulher. Dedicar-se somente ao trabalho é visto como antinatural para mulheres, como se a única missão feminina fosse prover a maternidade e garantir o bem estar da família (Carvalho, 2016). Picture Perfect (Paixão de Ocasião, 1997) manifesta a submissão desses valores sociais quando Kate Mosley (Jennifer Aniston) precisa mentir sobre possuir um noivo para conseguir uma promoção no trabalho. Cumprindo esse pré-requisito, seu chefe, Sr. Mercer (Kevin Dunn), considera-a como uma profissional responsável e realmente comprometida com o trabalho: "nós nos vestimos para o emprego que queremos ter, não para o emprego que temos", argumenta ele. Nos filmes, a mulher ainda é julgada por optar somente por uma carreira. A responsabilidade da gestão familiar confere-lhe uma dupla jornada involuntária imposta apenas às mulheres, além das expectativas de carreira. "Sem namorados e sem filhos, escolheu a carreira ao invés de uma família”, Henry (Samuel L. Jackson) fala para Helen (Carrie-Anne Moss) em Unthinkable (Ameaça Terrorista, 2010), como o motivo pelo qual ela foi escolhida.

A simbologia negativa relacionada ao estereótipo da liderança feminina é caracterizada na metáfora do Tokenismo, quando, apesar de ocuparem cargos elevados dentro das organizações, a autoridade da mulher é meramente simbólica (Zimmer, 1998). Nos filmes- 
objeto dessa pesquisa, essa associação aparece até mesmo no título. Ao usar a palavra "diabo", em The Devil Wears Prada (O Diabo Veste Prada, 2006), como adjetivo para descrever uma mulher em um alto cargo organizacional, o longa acaba passando uma mensagem prejudicial da liderança feminina, a partir dos símbolos (tokens) judaico-cristãos do bem associado à imagem de Deus e do mal na figura do Diabo.

Outro exemplo dessa metáfora é mostrado ao relacionar a competência da mulher com o visual que ela apresenta. A imagem é um fator atemporal pelo qual se exterioriza e incute um pensamento. Combinada com os elementos certos, emula a ideia de um padrão ideal (Strachicini, 2007). The Devil Wears Prada (O Diabo Veste Prada, 2006) apresenta Andy (Anne Hathaway) como competente jornalista. Entretanto, seu visual não se encaixa com o de uma revista de moda, assim ela recorre a Nigel (Stanley Tucci) para adequá-la a essa empresa. The Iron Lady (A Dama de Ferro, 2011) retrata concessões na aparência que Margaret Thatcher (Meryl Streep) faz com o objetivo de passar uma imagem mais humilde e, com isso, tornar-se primeira-ministra (Figura 4). Por fim, Bombshell (O Escândalo, 2019), traz como o visual das apresentadoras é crucial na televisão, usando sempre saias ou vestidos, mostrando sempre as pernas para atrair a audiência masculina (Figura 5).

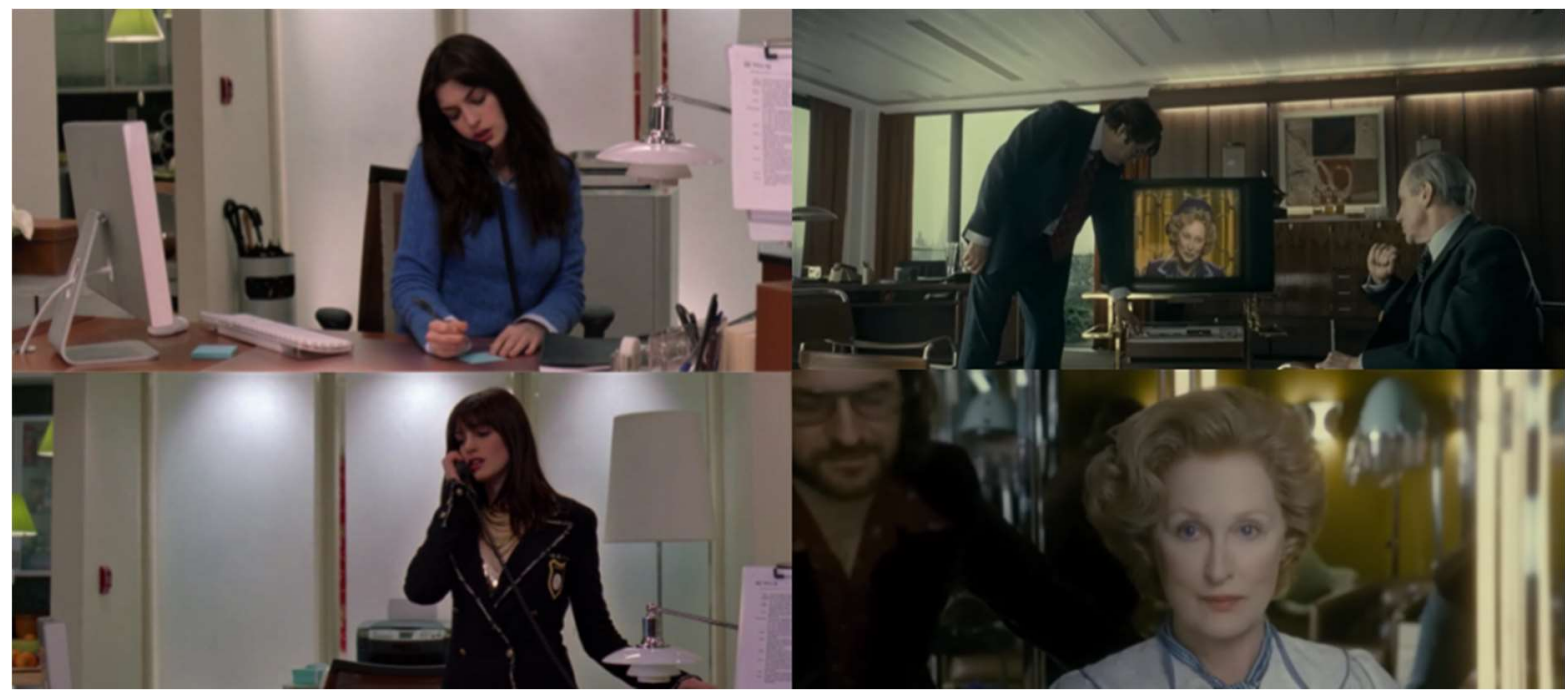

Figura 4. Transformações das personagens femininas

Fonte: O Diabo Veste Prada, 2006 (esquerda); A Dama de Ferro, 2011 (direita). Captura de tela realizada pelos autores. 


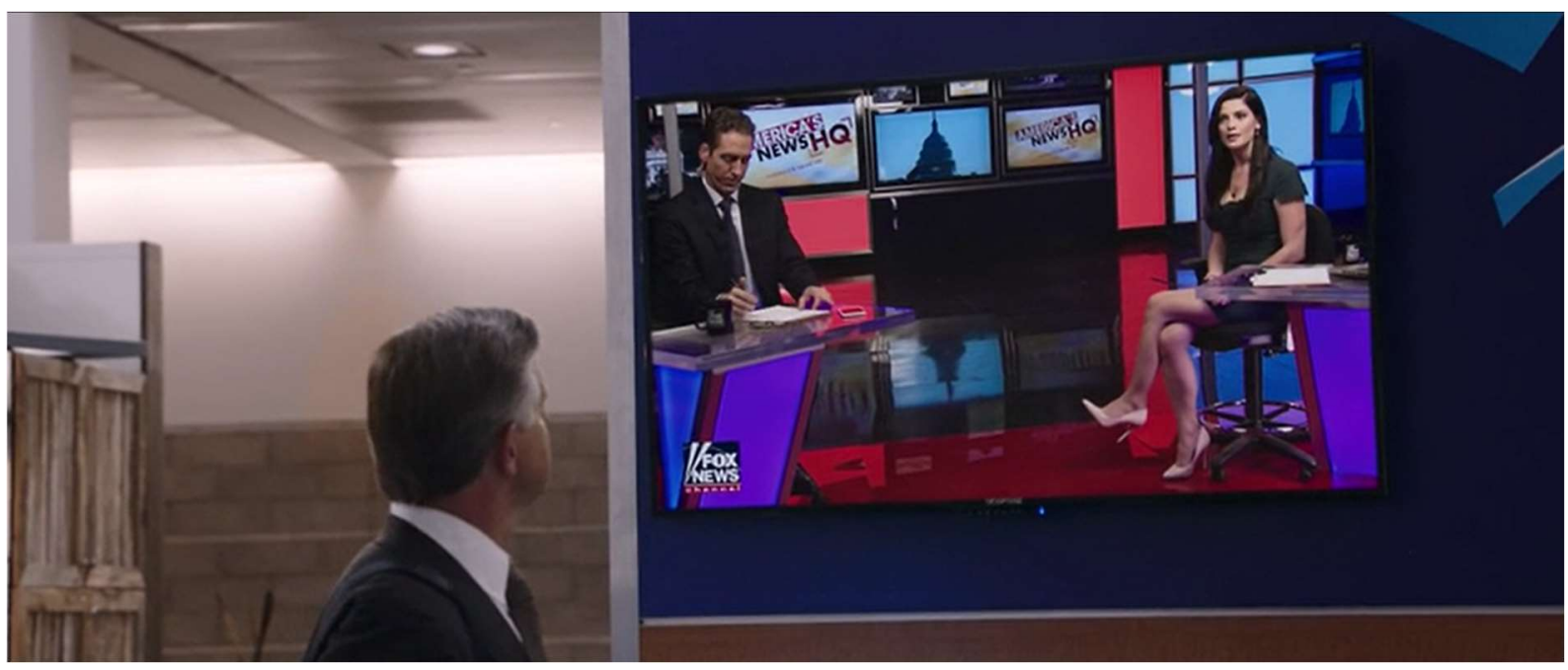

Figura 5. Homem começa a assistir o jornal devido ao enquadramento dado à âncora Fonte: O Escândalo, 2019. Captura de tela realizada pelos autores.

O cinema construiu a feminilidade da mulher como parte da cultura machista explorando a sua objetificação e colocando-a como passiva na narrativa (Dubois, 2001). Greta Garbo, Audrey Hepburn e Marlene Dietrich personificaram para Hollywood o estereótipo da mulher perfeita, silenciosa, sem emprego, objetificada e sem nada a oferecer além da beleza (Strachicini, 2007). Miss Congeniality 1 e 2 (Miss Simpatia 1 e 2, 2000, 2005) apresentam Grace Hart (Sandra Bullock) como uma agente de polícia "masculinizada", sem ajuste social, que não se importa com sua aparência. Porém ela precisa passar por uma mudança para entrar no concurso de Miss Estados Unidos, então torna-se uma mulher mais feminina, no primeiro filme e "a cara" da corporação, no segundo.

A utilização da protagonista em Miss Simpatia 2 com essa justificativa, evidencia um comportamento problemático que também se relaciona com essa metáfora enfrentada por mulheres no ambiente de trabalho. Com o argumento de que "feminilizar" a corporação usando a imagem da personagem de Sandra Bullock, ela é transformada em um token (símbolo), que não necessariamente representa o todo. Essa metáfora também é bastante comum no campo da política, percebida nos filmes A Conspiração (2000) e A Dama de Ferro (2011), em que as protagonistas de ambos os filmes ascendem, evidentemente por possuírem as competências necessárias, mas também devido à necessidade de representatividade de gênero implícita na sua nomeação.

\section{Considerações Finais}


Apesar das tramas selecionadas pertencerem a gêneros cinematográficos distintos (comédias, dramas, thrillers e romances), a construção das personagens, segundo as obras visitadas nesse artigo, evidenciou singularidades na abordagem na construção das protagonistas. O objetivo de analisar desafios e barreiras enfrentados por mulheres para avançar em suas carreiras em ambientes corporativos, representados pela indústria cinematográfica, através das lentes das metáforas de desigualdade de gênero foi alcançado. Observou-se que os filmes que constituíram o corpus da pesquisa apresentaram, em alguma cena, diálogo ou modo como a personagem principal é descrita dentro da narrativa pelo menos uma das metáforas abordadas (Teto de Vidro; Penhasco de Vidro; Fenômeno Abelha Rainha; Parede Materna; Segundo Turno; Labirinto; e Tokenismo).

As barreiras evidenciadas nas organizações e os compromissos familiares somam-se à exigência de adequação aos papéis estereotipadamente femininos. Então, as mulheres precisam estar sempre maquiadas, com vestimenta adequada ao cargo que ocupam e sempre estar de salto. Demonstrações excessivas de afetividade ou sensibilidade são mal vistas, pois não condizem com postos de liderança, bem como excesso de ambição ou agressividade, pois assim estabelecem fronteira muito próxima do universo masculino, o que faz essas mulheres sofrerem retaliação de pares e subordinados, sejam esses homens ou mulheres.

As limitações deste estudo se referem à utilização de palavras-chave para busca dos filmes apenas em inglês, que nos permitiu encontrar poucos filmes que não fossem dos Estados Unidos da América; e a impossibilidade de analisar os filmes em profundidade (e.g: Dubois, 2001 Strachicini, 2007; Spiker, 2012), devido ao volume de filmes que compuseram a base. Apesar dos limites da pesquisa, o objetivo proposto foi alcançado, de modo que o presente estudo contribui teoricamente para os estudos de gênero e trabalho por meio do exame crítico de mensagens sutis transmitidas por mídias cinematográficas, que funcionam como espelho da sociedade hodierna (Panayiotou, 2010) e produtores e reprodutores de desigualdades de gênero.

Para estudos futuros sobre como o cinema aborda mulheres de carreira, sugere-se a análise de filmes classificados como cult, a fim de examinar peculiaridades quanto à imagem da mulher de carreira reproduzida nestes filmes, que possuem público percebido como mais intelectualizado e crítico. Outrossim propõe-se exame aprofundado e comparativo de obras cinematográficas dirigidas por homens e por mulheres.

Finalmente, acredita-se que esse artigo contribui para o desenvolvimento de estudos sobre as metáforas que ilustram desigualdades de gênero no ambiente de trabalho, principalmente por discutir simultaneamente sete metáforas. O artigo apresenta o papel do cinema na produção e reprodução de desigualdades de gênero, ao mesmo tempo em que reflete 
o progresso das mulheres na ocupação de postos de comando e apresenta protagonistas que inspiram o desenvolvimento da carreira de mulheres reais.

\section{Referências}

Agarwal, A., Zheng, J., Kamath, S., Balasubramanian, S., \& Dey, S. A. (2015). Key female characters in film have more to talk about besides men: Automating the bechdel test. In Proceedings of the 2015 Conference of the North American Chapter of the Association for Computational Linguistics: Human Language Technologies (pp. 830-840).

Brailey, C. D., \& Slatton, B. C. (2019). Women, Work, and Inequality in the US: Revising the Second Shift. Journal of Sociology, 7(1), 29-35. https://doi.org/10.15640/jssw.v7n1a4.

Canabarro, J. R. S., \& Salvagni, J. (2015). Mulheres líderes: as desigualdades de gênero, carreira e família nas organizações de trabalho. Revista de Gestão e Secretariado, 6(2), 88-110. https://doi.org/10.7769/gesec.v6i2.347.

Carli, L. L., \& Eagly, A. H. (2016). Women face a labyrinth: An examination of metaphors for women leaders. Gender in Management: An International Journal. 31(8), 515-527. https://doi.org/10.1108/GM-02-2015-0007.

Carvalho, R. O. (2016). Sociedade, mulher e profissão. Revista de Gestão e Secretariado, 7(1), 27-44. https://doi.org/10.7769/gesec.v7i1.396.

Derks, B., Van Laar, C., \& Ellemers, N. (2016). The queen bee phenomenon: Why women leaders distance themselves from junior women. The Leadership Quarterly, 27(3), 456469. http://dx.doi.org/10.1016/j.leaqua.2015.12.007.

Derks, B., Ellemers, N., Van Laar, C., \& De Groot, K. (2011). Do sexist organizational cultures create the Queen Bee?. British Journal of Social Psychology, 50(3), 519-535. https://onlinelibrary.wiley.com/doi/abs/10.1348/014466610X525280.

Dowling, G. (2017). The glass ceiling: fact or a misguided metaphor?. Annals in Social Responsibility, 3(1), 23-41. https://doi.org/10.1108/ASR-05-2017-0002.

Dubois, D. (2001). 'Seeing the Female Body Differently': Gender issues in The Silence of the $\begin{array}{llll}\text { Lambs. Journal of } & \text { Gender }\end{array}$ https://doi.org/10.1080/09589230120086502.

Eagly, A. H., \& Carli, L. L. (2007). Through The Labyrinth: The Truth About How Women Become Leaders, Boston, MA. Harvard Business Review. 
Eagly, A. H., \& Carli, L. L. (2012). Women and the labyrinth of leadership. In W. E. Rosenbach, R. L. Taylor, \& M. A. Youndt (Eds.), Contemporary Issues in Leadership (7 ${ }^{\mathrm{a}}$ ed., pp. 147-162). Colorado: Westview Press.

Ezzedeen, S. R. (2015). Portrayals of career women in Hollywood films: implications for the glass ceiling's persistence. Gender in Management: An International Journal. http://dx.doi.org/10.1108/GM-07-2013-0073.

Finerman, W. (Producer), \& Frankel, D. (Director). (2006). The Devil Wears Prada [Motion picture]. United States: Twentieth Century Fox Film Corporation.

Gilbert, A. et al. (Producer), \& Roach, J. (Director). (2019). Bombshell [DVD]. United States: Bron Creative, Annapurna Pictures, Denver and Delilah Productions, Gramsci, Lighthouse Management \& Media, Creative Wealth Media.

Goetzman, G. (Producer), \& Demme, J. (Director). (1991). The Silence of the lambs [DVD]. United States: MCA Records.

Hatton, E., \& Trautner, M. N. (2013). Images of powerful women in the age of 'choice feminism'. Journal of Gender Studies, 22(1), 65-78. https://doi.org/10.1080/09589236.2012.681184.

Hochschild, A., \& Machung, A. (1989). Working parents and the revolution at home. New York: Viking.

Jones, D. (Producer), \& Lloyd, P. (Director). (2012). The Iron Lady [DVD]. United Kingdom: Pathé, Film4 Productions, UK Film Council, Goldcrest Films.

Laufer, J. (2005). La construction du plafond de verre: le cas des femmes cadres à potentiel. Travail et emploi, 2(102), 31-44. https://dares.travailemploi.gouv.fr/IMG/pdf/Laufer.pdf.

Loizos, P. Vídeo, filme e fotografias como documentos de pesquisa. In: Bauer, M. W.; Gaskell, G. Pesquisa qualitativa do texto: imagem e som: um manual prático. 2.ed. Petrópolis, RJ: Vozes, 2002. cap.6, p 137-155.

O'Leary-Kelly, A. M., \& Bowes-Sperry, L. (2001). Sexual harassment as unethical behavior: The role of moral intensity. Human Resource Management Review, 11(1-2), 73-92. https://doi.org/10.1016/S1053-4822(00)00041-3.

O’Neil, D. A., Hopkins, M. M., \& Bilimoria, D. (2008). Women's careers at the start of the 21st century: Patterns and paradoxes. Journal of Business Ethics, 80(4), 727-743. https://doi.org/10.1007/s10551-007-9465-6. 
Panayiotou, A. (2010). 'Macho 'managers and organizational heroes: competing masculinities in popular films. Organization, 17(6), 659-683. http://org.sagepub.com/content/17/6/659.

Pennell, H., \& Behm-Morawitz, E. (2015). The empowering (super) heroine? The effects of sexualized female characters in superhero films on women. Sex Roles, 72(5-6), 211-220. https://doi.org/10.1007/s11199-015-0455-3.

Pilcher, L. D., \& Silverstein, M. (2015). The MS. Factor: The Power of Female-Driven Content. Recuperado em 22 novembro, 2020, de https://cdn.ymaws.com/www.producersguild.org/resource/resmgr/WIN/ms_factor_090 115_01.pdf.

Schippers, M. (2007). Recovering the feminine other: Masculinity, femininity, and gender hegemony. Theory and society, 36(1), 85-102. https://doi.org/10.1007/s11186-0079022-4.

Smith, P., Caputi, P., \& Crittenden, N. (2012). A maze of metaphors around glass ceilings. Gender in Management: An International Journal, 27(7), 436-448. https://doi.org/10.1108/17542411211273432.

Spiker, J. A. (2012). Gender and power in the Devil Wears Prada. International Journal of Business, Humanities and Technology, 2(3), 16-26.

Strachicini, R. A. C. (2008). Miss Congeniality e It's a Wonderful Life: a marca discursivocultural norte-americana em Portugal e no Brasil. Dissertação de Mestrado, Universidade Presbiteriana Mackenzie, São Paulo, SP, Brasil. http://tede.mackenzie.br/jspui/handle/tede/2236.

Powell, G. N. (2012). Six ways of seeing the elephant: the intersection of sex, gender, and leadership. Gender in Management, 27(2), 119-141. https://doi.org/10.1108/17542411211214167.

Ryan, M. K., \& Haslam, S. A. (2005). The glass cliff: Evidence that women are overrepresented in precarious leadership positions. British Journal of management, 16(2), 81-90. https://doi.org/10.1111/j.1467-8551.2005.00433.x.

Ryan, M. K., \& Haslam, S. A. (2007). The glass cliff: Exploring the dynamics surrounding the appointment of women to precarious leadership positions. Academy of Management Review, 32(2), 549-572. https://doi.org/10.5465/amr.2007.24351856.

Vanoye, F., \& Goliot-Lété, A. (1994). Ensaio sobre a análise filmica. 2a. ed. Campinas: Papirus. 
Williams, J. C. (2004). The Maternal Wall. Harvard Business Review, 82(10), 26-27. https://hbr.org/2004/10/the-maternal-wall.

Zimmer, L. (1988). Tokenism and women in the workplace: The limits of gender-neutral theory. Social problems, 35(1), 64-77. https://doi.org/10.2307/800667.

Submetido em: 03.12 .2020

Aceito em: $\quad 31.05 .2021$ 